\title{
Emergence and Surveillance of Chikungunya
}

\author{
Federico Gobbi • Dora Buonfrate • Andrea Angheben • \\ Monica Degani • Zeno Bisoffi
}

Published online: 28 January 2015

(C) Springer International Publishing AG 2015

\begin{abstract}
Chikungunya virus (CHIKV), an arbovirus transmitted by Aedes mosquitoes, causes a disease characterised by fever, headache, skin rash, myalgias and severe arthralgias: the latter can persist for years. Following the first report in Africa in 1952, sporadic epidemics have been registered in Africa and in Asia before 2000. Since 2005, huge outbreaks have been reported, caused by globalisation (increasing displacement of humans and mosquitoes) and by an evolutionary success related to the adaptation of CHIKV to the mosquito vector: Therefore, CHIKV spread also in Europe, Oceania and the Americas. In endemic areas, seroprevalence studies could contribute to early detection of epidemics and to have a real picture of the burden of this disease. In temperate areas where Aedes aegypti and/or Aedes albopictus are present, CHIKV control measures require surveillance of imported and autochthonous cases, rapid diagnosis to detect local outbreaks and entomological surveillance.
\end{abstract}

Keywords Chikungunya virus $\cdot$ Mosquitoes $\cdot$ Aedes aegypti . Aedes albopictus · Outbreak · Reservoir · Sylvatic cycle · Urban cycle $\cdot$ Dengue virus $\cdot$ Human surveillance .

Entomological surveillance $\cdot$ Serosurvey $\cdot$ Health care system . Vector control

\section{Introduction}

Chikungunya virus (CHIKV) is an arbovirus transmitted by mosquitoes, mostly Aedes aegypti and Aedes albopictus. The

This article is part of the Topical Collection on Viral Tropical Medicine

F. Gobbi $(\bowtie) \cdot$ D. Buonfrate · A. Angheben $\cdot$ M. Degani $\cdot$ Z. Bisoffi

Centre for Tropical Diseases, Ospedale SacroCuore-Don Calabria,

Negrar, Verona, Italy

e-mail: federico.gobbi@sacrocuore.it virus probably originated in Africa, where it can still be found in non-human primates [1, 2], and presumably spread from Africa to Asia and to Americas two or more centuries ago. A relevant outbreak was registered in Batavia (now Jakarta) in 1779 and pandemic involving parts of the Western Hemisphere occurred in the 1820 s, presumably via sailing ships that carried Ae. aegypti mosquitoes [3]. Other historical outbreaks attributed to dengue virus (DENV) could have been caused by CHIKV [3]. The virus was first isolated in 1952 in a febrile patient during an outbreak on the Makonde Plateau, Southern Tanzania [4]. For a long time, the word "Chikungunya" was erroneously thought to derive from Swahili, while in reality the name originated from the Makonde language, spoken by an ethnic group living at the border between Southern Tanzania and Northern Mozambique. Chikungunya derives from the root verb "kungunyala", meaning "to become contorted" or "that which bends up" [5•].

CHIKV (family Togaviridae, genus Alphavirus) belongs to the Semliki Forest antigen complex that also includes Ross River virus, Mayaro, O'nyong-nyong virus, Getah, Bebaru and Semliki Forest virus [6]. Genetic analysis of the envelope glycoprotein sequences showed three different strains: the West African cluster, the East-Central and South African cluster (ECSA) and the Asian cluster [1]; to date, no differences in virulence between the three different lineages has been reported in humans [7]. CHIKV epidemics are characterised by sudden outbreaks alternating with periods of quiescence that can last for years or decades. Following the first report in Africa in 1952, sporadic epidemics have been registered in that continent and in Asia before 2000. Since 2000, huge outbreaks have been reported, caused by globalisation (increasing displacement of humans and mosquitoes) and by an evolutionary success related to the adaptation of CHIKV to the mosquito vector [8]. The first wave, started from Kenya in 2005 [9], affected African and Asian countries bordering the Indian 
Ocean, several islands of the latter and caused autochthonous cases also in continental Europe (Italy 2007 and France 2010) $[10,11]$ and Oceania (2011) [12]. The second wave, started in 2013 in Saint Barthélemy and still ongoing in 2014 [13••, 14], is responsible for several epidemics with autochthonous cases in North, Central and South America [15]. Currently, CHIKV is present in all continents, but Antarctica (Fig. 1).

CHIKV disease is usually characterised by fever, headache, skin rash, myalgias and severe arthralgias, after an incubation period ranging from 1 to 12 days, with an average of 2-4 days [6]. Asymptomatic subjects are estimated to account for 3 to $25 \%$ of the infected people. Arthralgia, the main and most disabling symptom, is usually symmetrical and involves fingers, wrists, elbows, ankles, knees and toes [6]. The affected joints may be swollen. The symptoms may resolve in 1 or 2 weeks, but a large proportion of patients (with an agerelated trend) complains of persistent arthralgias. Sissoko et al. reported recurrent episodes of polyartrhalgia in $57 \%$ of the patients, lasting up to 15 months after the infection [16]. Joints already affected by underlying disorders such osteoarthritis are particularly susceptible [6]. Neurological complications, although rare, are also reported and include encephalopathy, Guillain-Barré syndrome and acute flaccid paralysis $[17,18]$. The case-fatality rate for CHIKV is about 1 in $1000[19,20]$; most of the deaths have occurred in newborns, elderly people and adults with underlying disorders such as hypertension, cardiovascular or respiratory conditions [21].

The diagnosis of CHIKV is based on direct and indirect methods. The detection of CHIKV-RNA, based on detection of viral nucleic acid in serum samples by reverse-transcriptase PCR, results positive during the first week after symptom onset (viremic phase) and has an excellent sensitivity and specificity [22]. The indirect methods are based on antibody detection: Anti-CHIKV antibodies can be usually detected 5 days after symptom onset for IgM and a few days later for $\operatorname{IgG}[7,23]$. False positive and false negative results are possible, due to cross-reactivity with other viruses of the same family and to mixed cryoglobulinemia induced by CHIKV, respectively $[7,24]$.

There is no specific treatment, vaccine or preventive drug for CHIKV. Management is limited to painkillers and nonsteroidal anti-inflammatory drugs. Fever is usually high and poorly responsive to antipyretics. Aspirin should be avoided because of the risk of bleeding, and corticosteroids are not recommended, either, because of the strong rebound effect after stopping [7].

\section{Vectors and Reservoir}

Before 2000, only two epidemiological profiles of transmission of CHIKV were described. The first one is the classical African sylvatic cycle that involves several arboreal Aedes mosquitoes species as vectors (Ae. africanus, Ae. camptorhynchites, Ae. dalzieli, Ae. fulgens, Ae. furcifer, Ae. luteocefalus, Ae. vigilax and Ae. vittatus) and non-human primates as reservoir/amplifying hosts [6,25]. Some reports from Nigeria and Uganda indicate that Mansonia spp. mosquitoes, too, can transmit CHIKV [26]. The African Ae. furcifer, probably the principal enzootic vector, can also enter human villages and is presumably responsible for the transmission of the virus from monkeys to humans [27]. Occasional, small epidemics in rural areas resemble the pattern of sylvatic yellow fever and cause little impact on public health [7]. Some animals (birds, monkeys and rodents) are the reservoir of CHIKV during inter-epidemic periods, while humans constitute the

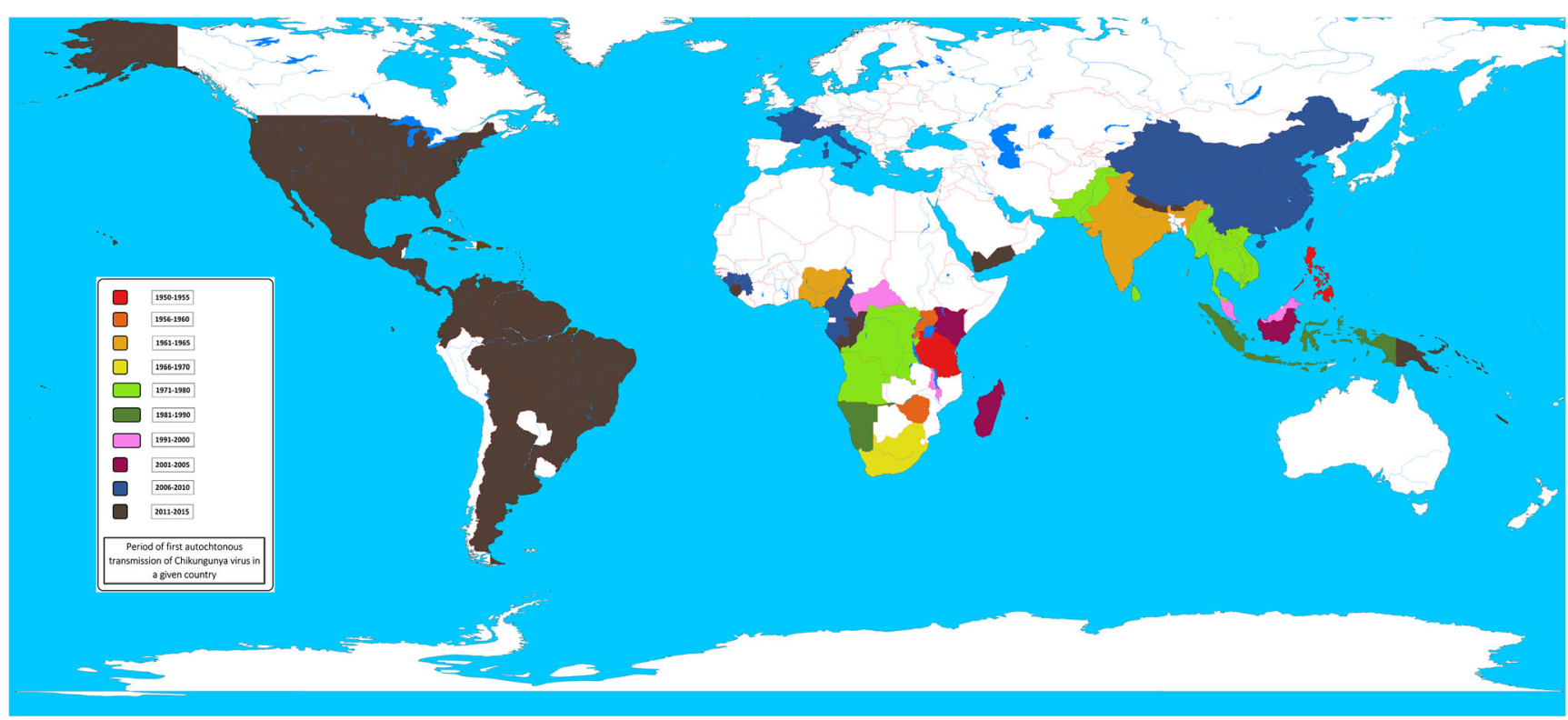

Fig. 1 Chronology of the first autochthonous CHIKV appearance in the different countries 
main reservoir during outbreaks. The classical Asian epidemiological profile is characterized instead by focal urban outbreaks caused by anthropophilic mosquitoes, mainly $A e$. aegypti, as observed in DENV. The urban human-mosquitohuman transmission cycle relies on the anthropophilic vectors Ae. aegypti and/or Ae. albopictus [25]. Mosquitoes themselves seem to be the main reservoir. Recent experimental studies confirmed the possible vertical transmission of the virus in Ae. aegypti from India, indicating a plausible survival mechanism of CHIKV during inter-epidemics periods [28••].

The cornerstone of the recent history of CHIKV was an adaptive mutation, alanine-to-valine substitution at position 226 in the E1 glycoprotein gene (E1:A226V), on an ECSACHIKV strain circulating in Reunion Island after September 2005 [8]. This enhanced the replication and transmission of CHIKV by Ae. albopictus, without affecting the vectorial capability of Ae. aegypti [29]. This new descendant of enzootic ECSA strain was named Indian Ocean lineage (IOL) [8]. IOL caused a third epidemiological profile characterised by explosive urban outbreaks both in tropical and in temperate countries [7]. So, if before 2005 Ae. albopictus could only occasionally transmit CHIKV, after 2005 this mosquito has become an excellent vector and this virus has become a threat for large parts of the world.

The behaviour of Ae. aegypti is suitable to cause massive urban outbreaks, because adult females prefer to feed on humans, take several blood meals during a single gonotrophic cycle, ovoposit in artificial containers and rest inside the houses [30]. Ae. albopictus, native of South-East Asia, is aggressive, silent, active all-day long, can survive cold winters and has a lifespan longer than other mosquitoes (up to 8 weeks) [25]. Moreover, it exclusively feeds on mammalian hosts with over $90 \%$ of blood meals derived from humans [31•]. In the last decades, climate changes (increasing temperatures, rainfall and humidity) and tyre exportation have caused new introduction of this mosquito to several, previously unaffected temperate areas, such as Europe and North America [25].

\section{Epidemiology of CHIKV by Continent}

We will outline below the main characteristics of CHIKV transmission, following the chronology of its appearance in the different continents, from Africa up to the most recent emergence in the Americas.

Africa After its first isolation in Tanzania in 1952 [4], cases of CHIKV were reported in several countries of sub-Saharian Africa between 1952 and 2000 [7]. Outbreaks were reported in Nigeria [32], Central African Republic [33], Uganda [34], Angola [35], Namibia [36], South Africa [37], Burundi [38] and Malawi [39]. The two different responsible strains were the West African cluster and the ECSA. Between 2000 and
2013, outbreaks or sporadic cases were reported in 2000 in the Democratic Republic of Congo [40], in 2006 in Cameroon [41], in Gabon [42] and in Guinea [43], in 2011 in the Republic of Congo [44] and in 2013 in Sierra Leone [45], while a recent study suggests endemic circulation of CHIKV in Tanzania [46•].

In 2004, an ECSA-CHIKV emerged in coastal towns of Kenya (Lamu and Mombasa) and in 2005-2006 it spread to Indian Ocean islands (Comoros, Seychelles, Mauritius, Reunion, Maldives and Madagascar) [47]. The outbreaks in Grande Comore Island and Reunion were particularly massive, considering that they involved, respectively, 65 and $35 \%$ of the total population of these islands [48, 49]. Moreover in 2005, in reunion, the above mentioned mutation of ECSA occurred [8], and the new strain IOL caused important outbreaks in other continents.

Asia Until 2005, only CHIKV Asian cluster, mainly transmitted by Ae. aegypti, was circulating. Its first appearance was in Philippines in 1954, with subsequent outbreaks in following years [50]. In 1963, CHIKV was detected for the first time in India [51]. In the 1970s, outbreaks or sporadic cases were reported in Southern and South-East Asia: Thailand, Sri Lanka, Vietnam, Pakistan, Cambodia, Laos and Myanmar [6]. Subsequently, incidence decreased in, with sporadic cases only. Between 1982 and 1985, the virus spread in Indonesia (South Sumatra, Java, Kalimantan, Sulawesi, Timor, Nusatengarra, Mollucas Islands and Iran Jaya) [6] and in the 1998 in Malaysia [52]. In the latter country, a new epidemic caused by CHIKV Asian cluster was reported in 2006 [53]. In the same year, the arrival of IOL from the Indian Ocean caused several outbreaks, transmitted by both Ae. albopictus and Ae. aegypti. In 2006, in India, a huge outbreak of IOL was reported, involving more than 1.39 million cases across ten states [54]. Subsequently, IOL caused epidemics in 2008 in Malaysia [55], Thailand [56] and Singapore [57]; in 2010 in China (Guandong province) [58] and Myanmar [59]; in 2011 in Cambodia [60], in 2012 in Bhutan [61], in Yemen [62] and in 2013 in Nepal [63].

Europe Autochthonous transmission has been first documented in 2007 in Italy, with an epidemic causing more than 200 cases (Emilia-Romagna Region) [10]. A seroprevalence survey carried out the following year reported an attack rate of $10 \%$. Only $18 \%$ of infected people resulted completely asymptomatic [64]. In 2010, two cases were detected in France (Department of Var) [11]. In both countries, transmission was caused by Ae. albopictus, the index case was a viremic traveller coming from the Indian subcontinent and the CHIKV strain was IOL. Field observations conducted during the spring of 2008 showed no evidence of infected overwintering progeny produced by Ae. Albopictus females infected during the 2007 outbreak in Italy [65]. Since its 
introduction at the end of the twentieth century, Ae. albopictus has become well established in large parts of Southern Europe [66]; therefore, several countries are at risk of introduction of CHIKV, mostly in the Mediterranean area. Transmission in this area seems to be only possible during the warm seasons. The vector is spreading to new areas, as reported in France $[67,68]$, where a recent study confirmed the high efficiency of temperate Ae. albopictus to transmit CHIKV [69•]. Mainland France is particularly at risk for introduction of CHIKV because of the huge number of travellers to and from its tropical departments located in Indian and Pacific Ocean and in the Caribbean sea.

Oceania The Oceania region, including Australia, New Zealand, Papua New Guinea (PNG) and the islands of the tropical Pacific Ocean, had never reported cases of CHIKV until February 2011 [70], when the virus caused an outbreak in New Caledonia [12]. During this epidemic, only 33 human cases were detected, due to effective public health measures and to the arrival of the cold season [70]. The vector involved in the transmission was Ae. aegypti and the strain was the Asian lineage. In June 2012, a new outbreak of CHIKV with more than 1500 cases was reported in Vanimo, PNG [71]. Subsequently, CHIKV spread to other eight provinces of PNG. The vector involved was Ae. albopictus and the strain was IOL. In 2013, an Asian cluster was responsible for a new outbreak in New Caledonia and in Yap State [72]. In 2014, epidemics are reported in Tonga, American Samoa, Samoa and Tokelau [72]. In Oceania, Ae. aegypti is present in all Pacific islands, except for New Zealand, Futuna and some small other islands [70, 73]. Ae. albopictus, that reached Oceania in the 1960s, is present in PNG, Australia (Torres Strait region), Fiji, Solomon, Tonga and probably Vanuatu [73].

In Queensland (Australia), imported cases from PNG were reported in 2013 and the presence of Ae. albopictus suggests the possibility of autochthonous transmission [72]. In New Zealand, at the moment neither Ae. aegypti nor Ae. albopictus is present, but the presence of the mosquito Coquillettidia iracunda, an aggressive human biter closely related to an efficient laboratory vector of CHIKV, constitutes a potentially threat [74].

Americas In November 2013, the first autochthonous cases of CHIKV in the Americas were reported. Five residents of Saint Martin, a French Caribbean island, reported fever followed by severe joint pain and resulted positive to CHIKV [13・•]. Subsequently, between the end of 2013 and 2014, CHIKV spread to several Caribbean islands (Guadaloupe, Martinique, Saint Barthélemy, Dominican Republic, St Kitts and Nevis, St Vincent) and French Guiana, causing more than 17,000 cases $[75,76]$. The Caribbeans are an area with frequent connecting flights among the islands and to mainland America and
Europe, considering that more than 10 million international visits are reported each year by WTO, of which $25 \%$ from Europe [77]. In fact, in 2014, a significant increase of CHIVK imported cases from the Caribbeans was reported in France and in Spain $[68,78]$. Local transmission of CHIKV in the Caribbeans was very effective. The initial reproduction number (mean number of secondary cases generated by an index case) ranged from 1 to 4 [79]. Therefore, this large outbreak of CHIKV quickly spread to several areas where the vectors were present. The two first autochthonous cases in continental USA were reported in Florida in July 2014 [80•]. Until October, 777,069 autochthonous cases of CHIKV were detected in the Americas, according to Pan American Health Organization (PAHO) [15]. Autochthonous cases were reported in North America (USA and Mexico), Central America (Costa Rica, Nicaragua, Guatemala and Panama), Latin Caribbean (Cuba, Dominican Republic, French Guiana, Guadaloupe, Martinique, Puerto Rico, Saint Bathelemy and Saint Martin), non-Latin Caribbeans (Antigua and Barbuda, Aruba, Barbados, Cayman Islands, Dominica, Jamaica, Montserrat, Suriname, Trinidad and Tobago and US Virgin Islands), Andean Area (Colombia, Ecuador and Venezuela) and Southern Cone (Argentina and Brazil) [15]. Sequence analysis demonstrated that this American outbreak is due to an Asian cluster of CHIKV, phylogenetically related to the Asian genotype strains recently circulating in Indonesia, China and the Philippines [14]. Vega-Rua studied the transmission efficiency (TE) of Ae. aegypti and Ae. albopictus, analyzing mosquitoes collected across the entire American continent and representing diverse climates, environments and ecotopes $[81 \bullet \cdot]$. The results are alarming, considering that the TE for all three CHIKV genotypes tested were $83.3 \%$ for Ae. aegypti and $96.7 \%$ for Ae. albopictus. So, both mosquitoes are highly competent to transmit CHIKV irrespective of the viral genotypes tested $[81 \bullet \bullet$. Because of there is no population immunity to CHIKV in Americas and considering the similarities between DENV and CHIKV, DENV might provide the best predictive model for the expected number of cases in the USA [82•]. In 2013, 2.4 million cases of DENV were reported in the Americas, including 773 travel related and 49 locally transmitted cases in the continental USA [82 •]. Considering that DENV is frequently asymptomatic and CHIKV is asymptomatic in less than $20 \%$ of the cases, the number of CHIKV cases could be much higher [80 ]. Moreover, because of the inflammatory response during an alphavirus infection in the joint is very similar to that in rheumatoid arthritis, Burt et al. predict that CHIKV infection might lead to exacerbation of underlying rheumatoid arthritis and other joint pathologies, so increasing the impact of CHIKV on the morbidity [83]. 


\section{Surveillance in Tropical Areas}

Surveillance of a specific disease, or group of diseases, is justified if targeted to appropriate actions.

In the case of CHIKV, no specific treatment is available, and therefore the clinical outcome is marginally, if at all, influenced by early detection. Control measures, on the other hand, are unlikely to abort an outbreak, at least in tropical areas where vector activity is all-year long. As is also true for DENV, that is transmitted by the same vectors, once an epidemic has started vector control measures are unlikely to significantly influence the epidemic curve. Moreover, a vaccine is not available. However, the prompt detection of a new outbreak would be crucial and should be combined, precisely, with the surveillance of DENV, that is also similar in clinical presentation and causes a major burden to public health. The geography of the two infections is very much the same, too, now that CHIKV has massively penetrated the American continent. Besides, DENV and CHIKV, undifferentiated febrile illnesses are common in people living in tropical areas of Africa, Asia, Oceania and America. The symptoms and differential diagnosis of these diseases are often similar and make accurate clinical diagnosis difficult without laboratory confirmation [84•]. The latter is therefore essential at the onset of a new epidemic, as well as during inter-epidemic periods. PCR or serology for CHIKV are often unavailable in low-income areas, making it impossible to distinguish CHIKV from other diseases and early detect a new outbreak. Clinical suspicion should be raised in case of fever and important joint pain, after ruling out, wherever indicated, malaria (thick film or rapid diagnostic tests (RDT)), DENV (NS1 antigen and IgM-IgG RDT) and other febrile conditions if possible. During interepidemic periods, serosurveys are rarely performed, thus missing an important opportunity to better understand CHIKV circulation [85]. However, some examples of active surveillance are reported. A study carried out in five South Asian countries to detect dengue and other causes of febrile diseases in children in inter-epidemic period reported that CHIKV was the most common one, accounting for $35 \%$ of all fevers [84•]. In Africa, seroprevalence studies performed in Kenya and Tanzania proved the endemic circulation of CHIKV, causing an important public health burden [46•, 85].

High resource health care systems in tropical areas have developed specific surveillance strategies. The Pacific Public Health Surveillance Network has planned a surveillance including efficient case detection and management, laboratory confirmation, vector control and breeding site elimination, as well as information and communication strategies [72]: in some Caribbean Islands, public education was promoted through radio spots, television, distribution of flyers and poster with prevention messages readily available in public areas, airports, hospitals and clinics [75].

\section{Surveillance in Non-Endemic Areas}

In Europe, CHIKV outbreaks might occur if a viremic traveller enters areas where the vector is present and environmental conditions are suitable for the transmission of the virus [86]. Tilston et al. defined as high priority surveillance zones those where the vector has the potential to overwinter, and seasonal temperatures favour the development of adult Ae. Albopictus and viral transmission. They concluded that CHIKV epidemics can occur mostly where/when average monthly temperatures exceed $20{ }^{\circ} \mathrm{C}$. In the Northern Hemisphere, the most probable period is between June and September, as happened in 2007 in Italy [10] when the outbreak started in June (mean monthly temperature around $22{ }^{\circ} \mathrm{C}$ ) and subsided in September when the temperatures fell below $20^{\circ} \mathrm{C}$ [86]. In Europe, the countries considered at higher risk so far are France and Italy, receiving a large number of potentially viremic visitors each year [86]. Spain should be probably added, as the ongoing outbreak in the Americas caused a sharp increase of the imported cases of CHIKV recorded in 2014 in that country, as well as in France $[80 \bullet, 68]$. In the Americas, CHIKV is expected to remain endemic in the tropical areas. Therefore, temperate areas with a seasonal presence of Ae. aegypti and/or Ae. albopictus are at risk during the warm season. CHIKV control measures require entomological surveillance, surveillance of imported and autochthonous cases and rapid diagnosis to detect local outbreaks $[5 \cdot, 87]$. The main objective of human surveillance is to increase the detection rate of imported CHIKV and DENV cases in travellers from endemic areas, including new immigrants and settled immigrants visiting relatives and friends (VFR), and to promptly identify potential autochthonous cases. Every febrile traveller from endemic areas should be promptly tested for malaria, DENV and CHIKV. According to the special surveillance of "summer fevers" in Veneto region, Northern Italy, every febrile $\left(\geq 38^{\circ} \mathrm{C}\right)$ traveller recently returned from endemic countries, after malaria and other obvious causes of fever have been ruled out, is considered as a possible case of DENV or CHIKV [88]. For DENV, RDT with good sensitivity and specificity are available [89]: in case of positivity, the patient is considered a probable case and samples are sent to a referral laboratory for confirmation (PCR and viral isolation). Unfortunately, an antigen RDT is not available for CHIKV and the sensitivity of RDT (for detection of $\operatorname{IgM}$ and $\operatorname{IgG}$ ) is poor, especially during the first few days of fever. In fact, a large proportion of confirmed CHIKV cases were missed by RDT [90]. A possible solution, according to a recent study [91 ••], could be RT-PCR on driedblood spots collected on filter paper, to be promptly send to a reference laboratory. In the same region, the main objective of entomological surveillance is to detect DENV or CHIKV in $A e$. albopictus vectors, in case a viremic human case is detected [92••]. Appropriate vector control measures are implemented within $200 \mathrm{~m}$ of the places visited by the patient during the likely viremic period. In case a locally acquired case is 
confirmed, active case finding is immediately started and entomological investigations, as well as vector control measures, are intensified. Information and education activities about personal protection and reduction of mosquito breeding sites should be an essential component of any DENV and/or CHIKV control programme [68]. Moreover, considering that the control of $A e$. Albopictus is particularly difficult, requiring access to private yards and residences, homeowners are essential participants in the vector control process as was shown by a recent study [93]. Active education, using community peer educators, caused a $22.6 \%$ reduction in container habitats in the intervention communities, compared to $32.3 \%$ in control sites [93].

\section{Conclusions}

The spread of CHIKV over the past decades is a good example of globalisation of pathogens. An originally "local" virus has gradually spread from one continent to another, until only a very small portion of our planet can be still considered free. Not a devastating illness in itself, recent studies since 2006 have shown nevertheless that fatal cases do occur, especially in, but not limited to, elderly patients and/or subjects with underlying, chronic clinical conditions. Moreover, the often long persistence of rheumatic pain, poorly responding to treatment, is a challenge. The need of effective surveillance systems allowing prompt detection of new outbreaks cannot be overemphasised and should not be limited to a given disease. CHIKV surveillance should be integrated in a broader surveillance of unexplained febrile illnesses, according to global and local epidemiology and considering, once again, that we live in a global village where many infections cannot be considered "exotic" any longer.

\section{Compliance with Ethics Guidelines}

Conflict of Interest Federico Gobbi, Dora Buonfrate, Andrea Angheben, Monica Degani and Zeno Bisoffi declare that they have no conflict of interest.

Human and Animal Rights and Informed Consent This article does not contain any studies with human or animal subjects performed by any of the authors.

\section{References}

Papers of particular interest, published recently, have been highlighted as:

- Of importance

•. Of major importance

1. Volk SM, Chen R, Tsetsarkin KA, et al. Genome-scale phylogenetic analyses of chikungunya virus reveal independent emergences of recent epidemics and various evolutionary rates. J Virol. 2010;84:6497-504.
2. Powers AM, Brault AC, Tesh RB, Weaver SC. Re-emergence of chikungunya and o'nyong-nyong viruses: evidence for distinct geographical lineages and distant evolutionary relationships. J Gen Virol. 2000;81:471-9.

3. Carey DE. Chikungunya and dengue: a case of mistaken identity. J Hist Med Allied Sci. 1971;26:243-62.

4. Robinson MC. An epidemic of virus disease in Southern Province, Tanganyika Territory, in 1952-53. I. Clinical features. Trans R Soc Trop Med Hyg. 1955;49:28-32.

5. Morens DM, Fauci AS. Chikungunya at the door-déjà vu all over again? N Engl J Med. 2014;371(10):885-7. This paper states that CHIKV in the Americas is a new important threat, similar to DENV, with a potential to become established in the Western Hemisphere. This is a challenge for the Public Health in the vector control and for the clinicians in diagnosing and reporting the disease.

6. Burt FJ, Rolph MS, Rulli NE, Mahalingam S, Heise MT. Chikungunya: a re-emerging virus. Lancet. 2012;379(9816): 662-71.

7. Simon F, Javelle E, Oliver M, Leparc-Goffart I, Marimoutou C. Chikungunya virus infection. Curr Infect Dis Rep. 2011;13(3): 218-28.

8. Schuffenecker I, Iteman I, Michault A, et al. Genome microevolution of chikungunya viruses causing the Indian Ocean outbreak. PLoS Med. 2006;3:1058-70.

9. Chretien JP, Anyamba A, Bedno SA, Breiman RF, Sang R, Sergon $\mathrm{K}$, et al. Drought-associated chikungunya emergence along coastal East Africa. Am J Trop Med Hyg. 2007;76(3):405-7.

10. Rezza G, Nicoletti L, Angelini K, et al. Infection with chikungunya virus in Italy: an outbreak in a temperate region. Lancet. 2007;370: 1840-6.

11. Gould EA, Gallian P, De Lamballerie X, Charrel RN. First cases of autochthonous dengue fever and chikungunya fever in France: from bad dream to reality! Clin Microbiol Infect. 2010;16(12):1702-4.

12. Dupont-Rouzeyrol M, Caro V, Guillaumot L, Vazeille M, D’Ortenzio E, Thiberge JM, et al. Chikungunya virus and the mosquito vector Aedes aegypti in New Caledonia (South Pacific Region). Vector Borne Zoonotic Dis. 2012;12(12):1036-41.

13.• Cassadou S, Boucau S, Petit-Sinturel M, Huc P, Leparc-Goffart I, Ledrans M. Emergence of chikungunya fever on the French side of Saint Martin island, October to December 2013. Eur Surveill. 2014;19(13). This paper describes the first autochthonous cases of CHIKV in the Americas, indicating a risk of epidemics in this continent and in Europe.

14. Leparc-Goffart I, Nougairede A, Cassadou S, Prat C, de Lamballerie X. Chikungunya in the Americas. Lancet. 2014;383(9916):514.

15. ProMed. 20 oct 2014. Chikungunya. Americas. 20142010.2881135.

16. Sissoko D, Malvy D, Ezzedine K, et al. Post-epidemic Chikungunya disease on Reunion Island: course of rheumatic manifestations and associated factors over a 15-month period. PLoS Negl Trop Dis. 2009;3:e389.

17. Rampal M, Sharda M, Meena H. Neurological complications in Chikungunya fever. J Assoc Physicians India. 2007;55:765-9.

18. Wielanek AC, Monredon JD, Amrani ME, Roger JC, Serveaux JP. Guillain-Barre syndrome complicating a Chikungunya virus infection. Neurology. 2007;69:2105-7.

19. Borgherini G, Poubeau P, Staikowsky F, et al. Outbreak of chikungunya on Reunion Island: early clinical and laboratory features in 157 adult patients. Clin Infect Dis. 2007;44:1401-7.

20. Queyriaux B, Simon F, Grandadam M, Michel R, Tolou H, Boutin JP. Clinical burden of chikungunya virus infection. Lancet Infect Dis. 2008;8:2-3.

21. Economopoulou A, Dominguez M, Helynck B, et al. Atypical Chikungunya virus infections: Clinical manifestations, mortality and risk factors for severe disease during the 2005-2006 outbreak on Reunion. Epidemiol Infect. 2009;137:534-41. 
22. Panning M, Hess M, Fischer W, et al. Performance of the RealStar Chikungunya virus real-time reverse transcription-PCR kit. J Clin Microbiol. 2009;47:3014-6.

23. Niedrig M, Zeller H, Schuffenecker I, et al. International diagnostic accuracy study for the serological detection of chikungunya virus infection. Clin Microbiol Infect. 2009;15:880-4.

24. Oliver M, Grandadam M, Marimoutou C, et al. Persisting mixed cryoglobulinemia in Chikungunya infection. PLoS Negl Trop Dis. 2009;3:e374.

25. Caglioti C, Lalle E, Castilletti C, Carletti F, Capobianchi MR, Bordi L. Chikungunya virus infection: an overview. New Microbiol. 2013;36(3):211-27.

26. Jupp PG, McIntosh BM, Dos Santos I, de Moor P. Laboratory vector studies on six mosquito and one tick species with chikungunya virus. Trans R Soc Trop Med Hyg. 1981;75:15-9.

27. Peyrefitte CN, Rousset D, Pastorino BA, et al. Chikungunya virus, Cameroon, 2006. Emerg Infect Dis. 2007;13:768-71.

28.• Agarwal A, Dash PK, Singh AK, Sharma S, Gopalan N, Rao PV, et al. Evidence of experimental vertical transmission of emerging novel ECSA genotype of Chikungunya Virus in Aedes aegypti. PLoS Negl Trop Dis. 2014;8(7):e2990. This study confirms the possible vertical transmission of the virus in Ae. aegypti from India, indicating a plausible survival mechanism of CHIKV during inter-epidemics periods.

29. Tsetsarkin KA, Vanlandingham DL, McGee CE, Higgs S. A single mutation in chikungunya virus affects vector specificity and epidemic potential. PLoS Pathog. 2007;3:1895-906.

30. Weaver SC, Osorio JE, Livengood JA, Chen R, Stinchcomb DT. Chikungunya virus and prospects for a vaccine. Expert Rev Vaccines. 2012;11(9):1087-101.

31. Faraji A, Egizi A, Fonseca DM, Unlu I, Crepeau T, Healy SP, et al. Comparative host feeding patterns of the Asian tiger mosquito, Aedes albopictus, in urban and suburban Northeastern USA and implications for disease transmission. PLoS Negl Trop Dis. 2014;8(8):e3037. This study reports that Ae. albopictus exclusively feeds on mammalian hosts with over $90 \%$ of blood meals derived from humans.

32. Moore DL, Causey OR, Carey DE, et al. Arthropod-borne viral infections of man in Nigeria, 1964-1970. Ann Trop Med Parasitol. 1975;69:49-64.

33. Guilherme JM, Gonella-Legall C, Legall F, Nakoume E, Vincent J. Seroperevalence of five arboviruses in Zebu cattle in the Central African Republic. Trans R Soc Trop Med Hyg. 1996;90:31-3.

34. Weinbren MP, Haddow AJ, Williams MC. The occurrence of chikungunya virus in Uganda. I. Isolation from mosquitoes. Trans R Soc Trop Med Hyg. 1958;52:253-62.

35. Filipe AF, Pinto MR. Arbovirus studies in Luanda, Angola. 2. Virological and serological studies during an outbreak of denguelike disease caused by chikungunya virus. Bull World Health Organ. 1973;49:37-40.

36. Joubert JJ, Prozesky OW, Lourens JG, et al. Prevalence of hepatitis virus and some arbovirus infections in Kavango, northern SWA/ Namibia. S Afr Med J. 1985;30:500-2.

37. Kaschula VR, Van Dellen AF, de Vos V. Some infectious diseases of wild vervet monkeys (Cercopythicus aethiopsepygerythrus) in South Africa. J S Afr Vet Assoc. 1978;49:223-7.

38. Rodhain F, Carteron B, Laroche R, Hannoun C. Human arbovirus infections in Burundi: results of a seroepidemiologic survey, 19801982. Bull Soc Pathol Exot Fil. 1987;80:155-61.

39. Van den Bosch C, Lloyd G. Chikungunya fever as a risk factor for endemic Burkitt's lymphoma in Malawi. Trans R Soc Trop Med Hyg. 2000;94:704-5.

40. Pastorino B, Muyembe-Tamfum JJ, Bessaud M, et al. Epidemic resurgence of Chikungunya virus in Democratic Republic of the Congo: identification of a new central Africa strain. J Med Virol. 2004;74:277-82.
41. Kuniholm MH, Wolfe ND, Huang CY, Mpoudi-Ngole E, Tamoufe $\mathrm{U}$, LeBreton $\mathrm{M}$, et al. Seroprevalence and distribution of Flaviviridae, Togaviridae, and Bunyaviridae arboviral infections in rural Cameroonian adults. Am J Trop Med Hyg. 2006;74(6): 1078-83.

42. Peyrefitte CN, Bessaud M, Pastorino BA, Gravier P, Plumet S, Merle OL, et al. Circulation of Chikungunya virus in Gabon, 2006-2007. J Med Virol. 2008;80(3):430-3.

43. Jentes ES, Robinson J, Johnson BW, et al. Acute arboviral infections in Guinea, west Africa, 2006. Am J Trop Med Hyg. 2010;83: 388-94.

44. Mombouli JV, Bitsindou P, Elion DO, Grolla A, Feldmann H, Niama FR, et al. Chikungunya virus infection, Brazzaville, Republic of Congo, 2011. Emerg Infect Dis. 2013;19(9):1542-3. doi:10.3201/eid1909.130451.

45. Ansumana R, Jacobsen KH, Leski TA, Covington AL, Bangura U, Hodges $\mathrm{MH}$, et al. Reemergence of chikungunya virus in Bo, Sierra Leone. Emerg Infect Dis. 2013;19(7):1108-10.

46. Weller N, Clowes P, Dobler G, Saathoff E, Kroidl I, Ntinginya NE, et al. Seroprevalence of alphavirus antibodies in a cross-sectional study in southwestern Tanzania suggests endemic circulation of chikungunya. PLoS Negl Trop Dis. 2014;8(7):e2979. This study demonstrates that CHIKV is not regularly diagnosed in the health facilities in Tanzania, and might be overlooked by medical staff as a possible causative agent for febrile illness.

47. Charrel RN, Lamballerie X, Raoult D. Chikungunya outbreaksthe globalization of vectorborne diseases. N Engl J Med. 2007;356: 769-71.

48. Sergon K, Yahay AA, Brown J, et al. Seroprevalence of chikungunya virus infections on Grande Comore Island, Union of the Comoros, 2005. Am J Trop Med Hyg. 2007;76:1189-93.

49. Renault P, Solet J-L, Sissoko D, et al. A major epidemic of chikungunya virus infection on Reunion Island, France, 20052006. Am J Trop Med Hyg. 2007;77:727-31.

50. Hammon WM, Rudnick A, Sather GE. Viruses associated with epidemic hemorrhagic fevers of the Philippines and Thailand. Science. 1960;131(3407):1102-3.

51. Shah KV, Gibbs Jr CJ, Banerjee G. Virological investigation of the epidemic of haemorrhagic fever in Calcutta: Isolation of three strains of chikungunya virus. Indian J Med Res. 1964;52:676-83.

52. Lam SK, Chua KB, Hooi PS, Rahimah MA, Kumari S, Tharmaratnam $\mathrm{M}$, et al. Chikungunya infection - an emerging disease in Malaysia. Southeast Asian J Trop Med Public Health. 2001;32(3):447-51.

53. Abubakar S, Sam IC, Wong PF, MatRahim N, Hooi PS, Roslan N. Reemergence of endemic Chikungunya, Malaysia. Emerg Infect Dis. 2007;13(1):147-9.

54. Mavalankar D, Shastri P, Raman P. Chikungunya epidemic in India: a major public-health disaster. Lancet Infect Dis. 2007;7(5):306-7.

55. Sam IC, Chan YF, Chan SY, Loong SK, Chin HK, Hooi PS, et al. Chikungunya virus of Asian and Central/East African genotypes in Malaysia. J Clin Virol. 2009;46(2):180-3.

56. Rianthavorn P, Prianantathavorn K, Wuttirattanakowit N, Theamboonlers A, Poovorawan Y. An outbreak of chikungunya in southern Thailand from 2008 to 2009 caused by African strains with A226V mutation. Int J Infect Dis. 2010;14 Suppl 3:e161-5.

57. Leo YS, Chow AL, Tan LK, Lye DC, Lin L, Ng LC. Chikungunya outbreak, Singapore, 2008. Emerg Infect Dis. 2009;15(5):836-7.

58. Wu D, Wu J, Zhang Q, Zhong H, Ke C, Deng X, et al. Chikungunya outbreak in Guangdong Province, China, 2010. Emerg Infect Dis. 2012;18(3):493-5.

59. Tun MM, Thant KZ, Inoue S, Nabeshima T, Aoki K, Kyaw AK, et al. Detection of east/central/south African genotype of chikungunya virus in Myanmar, 2010. Emerg Infect Dis. 2014;20(8):1378-81. 
60. Duong V, Andries AC, Ngan C, Sok T, Richner B, AsgariJirhandeh N, et al. Reemergence of Chikungunya virus in Cambodia. Emerg Infect Dis. 2012;18(12):2066-9.

61. Wangchuk S, Chinnawirotpisan P, Dorji T, Tobgay T, Dorji T, Yoon IK, et al. Chikungunya fever outbreak, Bhutan, 2012. Emerg Infect Dis. 2013;19(10):1681-4.

62. Rezza G, El-Sawaf G, Faggioni G, Vescio F, Al Ameri R, De Santis R, et al. Co-circulation of Dengue and Chikungunya viruses, Al Hudaydah, Yemen, 2012. Emerg Infect Dis. 2014;20(8):1351-4.

63. Pun SB, Bastola A, Shah R. First report of Chikungunya virus infection in Nepal. J Infect Dev Ctries. 2014;8(6):790-2.

64. Moro ML, Gagliotti C, Silvi G, Angelini R, Sambri V, Rezza G, et al. Chikungunya virus in North-Eastern Italy: a seroprevalence survey. Am J Trop Med Hyg. 2010;82(3):508-11.

65. Bellini R, Medici A, Calzolari M, Bonilauri P, Cavrini F, Sambri V, et al. Impact of Chikungunya virus on Aedes albopictus females and possibility of vertical transmission using the actors of the 2007 outbreak in Italy. PLoS One. 2012;7(2):e28360.

66. Fischer D, Thomas SM, Neteler M, Tjaden NB, Beierkuhnlein C. Climatic suisility of Aedes albopictus in Europe referring to climate change projections: comparison of mechanistic and correlative niche modelling approaches. Eur Surveill. 2014;19(6)

67. Marchand E, Prat C, Jeannin C, Lafont E, Bergmann T, Flusin O, et al. Autochthonous case of dengue in France, October 2013. Eur Surveill. 2013;18(50):20661.

68. Paty MC, Six C, Charlet F, Heuzé G, Cochet A, Wiegandt A, et al. Large number of imported chikungunya cases in mainland France, 2014: a challenge for surveillance and response. Eur Surveill. 2014;19(28):20856.

69. Vega-Rua A, Zouache K, Caro V, Diancourt L, Delaunay P, Grandadam M, et al. High efficiency of temperate Aedes albopictus to transmit chikungunya and dengue viruses in the Southeast of France. PLoS One. 2013;8(3):e59716. This study confirms the high efficiency of Ae. Albopictus living in Southeast of France to transmit DENV and CHIKV.

70. Horwood P, Bande G, Dagina R, Guillaumot L, Aaskov J, Pavlin B. The threat of chikungunya in Oceania. W Pac Surveill Response J. 2013;4(2):8-10.

71. Horwood PF, Reimer LJ, Dagina R, Susapu M, Bande G, Katusele $\mathrm{M}$, et al. Outbreak of chikungunya virus infection, Vanimo, Papua New Guinea. Emerg Infect Dis. 2013;19(9):1535-8.

72. Roth A, Hoy D, Horwood PF, Ropa B, Hancock T, Guillaumot L, Rickart K, Frison P, Pavlin B, Souares Y. Preparedness for threat of chikungunya in the pacific. Emerg Infect Dis. 2014; 20(8).

73. Guillaumot L, Ofanoa R, Swillen L, Singh N, Bossin HC, Schaffner F. Distribution of Aedes albopictus (Diptera, Culicidae) in southwestern Pacific countries, with a first report from the Kingdom of Tonga. Parasit Vectors. 2012;5:247.

74. Derraik JG, Slaney D, Nye ER, Weinstein P. Chikungunya virus: a novel and potentially serious threat to New Zealand and the South Pacific islands. Am J Trop Med Hyg. 2010;83(4):755-9.

75. Van Bortel W, Dorleans F, Rosine J, Blateau A, Rousset D, Matheus $\mathrm{S}$, et al. Chikungunya outbreak in the Caribbean region, December 2013 to March 2014, and the significance for Europe. Eur Surveill. 2014;3:19(13).

76. Nasci RS. Movement of chikungunya virus into the Western hemisphere. Emerg Infect Dis. 2014;20(8):1394-5.

77. Dehoorne O, Murat C, Petit-Charles N. International tourism in the Caribbean area: current status and future prospects. Etudes caribéennes. 2010;16. Available from: http://etudescaribeennes. revues.org/4713. doi: 10.4000/etudescaribeennes.4713. http://dx. doi.org/10.4000/etudescaribeennes.4713.
78. Requena-Méndez A, Garcia C, Aldasoro E, Vicente JA, Martínez MJ, Pérez-Molina JA, et al. Cases of chikungunya virus infection in travellers returning to Spain from Haiti or Dominican Republic, April-June 2014. Eur Surveill. 2014;19(28):20853.

79. Cauchemez S, Ledrans M, Poletto C, Quenel P, de Valk H, Colizza $\mathrm{V}$, et al. Local and regional spread of chikungunya fever in the Americas. Eur Surveill. 2014;19(28):20854.

80. Kuehn BM. Chikungunya virus transmission found in the United States: US health authorities brace for wider spread. JAMA. 2014;312(8):776-7. This paper confirms the first autochthonous cases of CHIKV in the USA, highlighting the future implications in this country.

81.•• Vega-Rúa A, Zouache K, Girod R, Failloux AB, Lourenço-deOliveira R. High level of vector competence of Aedes aegypti and Aedes albopictus from ten American countries as a crucial factor in the spread of Chikungunya virus. J Virol. 2014;88(11): 6294-306. This study reports the transmission efficiency (TE) of Ae. aegypti and Ae. albopictus, analyzing mosquitoes collected across the entire American continent and representing diverse climates, environments and ecotopes. The results are alarming, considering that the TE for all three CHIKV genotypes tested were $83.3 \%$ for Ae. aegypti and $96.7 \%$ for Ae. albopictus.

82. Staples JE, Fischer M. Chikungunya virus in the Americas - what a vectorborne pathogen can do. N Engl J Med. 2014;371(10):887-9. This paper, describing the past DENV outbreak in the Americas, gives a predictive model for the expected course of CHIKV in the USA.

83. Burt F, Chen W, Mahalingam S. Chikungunya virus and arthritic disease. Lancet Infect Dis. 2014;14(9):789-90.

84. Capeding MR, Chua MN, Hadinegoro SR, Hussain II, Nallusamy R, Pitisuttithum P, et al. Dengue and other common causes of acute febrile illness in Asia: an active surveillance study in children. PLoS Negl Trop Dis. 2013;7(7):e2331. This paper defines the burden of CHIKV with an active surveillance of fevers in children in an endemic area during an interepidemic period.

85. Sutherland LJ, Cash AA, Huang YJ, Sang RC, Malhotra I, Moormann AM, et al. Serologic evidence of arboviral infections among humans in Kenya. Am J Trop Med Hyg. 2011;85(1):158-61.

86. Tilston N, Skelly C, Weinstein P. Pan-European Chikungunya surveillance: designing risk stratified surveillance zones. Int J Health Geogr. 2009;8:61.

87. Noël H, Rizzo C. Spread of chikungunya from the Caribbean to mainland Central and South America: a greater risk of spillover in Europe? Eur Surveill. 2014;19(28):20855.

88. Gobbi F, Barzon L, Capelli G, Angheben A, Pacenti M, Napoletano $\mathrm{G}$, et al. Surveillance for West Nile, dengue, and chikungunya virus infections, Veneto Region, Italy, 2010. Emerg Infect Dis. 2012;18(4):671-3.

89. Andries AC, Duong V, Ngan C, et al. Field evaluation and impact on clinical management of a rapid diagnostic kit that detects dengue NS1, IgM and IgG. PLoS Negl Trop Dis. 2012;6(12):e1993.

90. Rianthavorn P, Wuttirattanakowit N, Prianantathavorn K, Limpaphayom N, Theamboonlers A, Poovorawan Y. Evaluation of a rapid assay for detection of IgM antibodies to chikungunya. Southeast Asian J Trop Med Public Health. 2010;41(1):92-6.

91.• Andriamandimby SF, Heraud JM, Randrianasolo L, Rafisandratantsoa JT, Andriamamonjy S, Richard V. Dried-blood spots: a cost-effective field method for the detection of Chikungunya virus circulation in remote areas. PLoS Negl Trop Dis. 2013;7(7):e2339. This study evaluated the use of capillary blood samples blotted on filter paper for 
molecular diagnosis (RT-PCR) and demonstrated a good sensitivity and specificity of this method (93.1\% and $94.4 \%$, respectively), suggesting that it can be a cost-effective tool for surveillance of CHIKV in endemic and non-endemic areas.

92.• Gobbi F, Capelli G, Angheben A, Giobbia M, Conforto M, Franzetti M, et al. Human and entomological surveillance of West Nile fever, dengue and chikungunya in Veneto Region, Italy, 2010-2012. BMC Infect Dis. 2014;14:60. This study highlights the possibility of an integrated human and entomological surveillance in non endemic areas, to have a real picture of a circulation of these three viruses and to promptly identify potential autochthonous cases of CHIKV and DENV.

93. Healy K, Hamilton G, Crepeau T, Healy S, Unlu I, Farajollahi $\mathrm{A}$, et al. Integrating the public in mosquito management: active education by community peers can lead to significant reduction in peridomestic container mosquito habitats. PLoS One. 2014;9(9):e108504. 